\title{
Role of High-dose Chemotherapy and Autologous Stem Cell Transplantation for Relapsed Ewing's Sarcoma: A Case Report with Focused Review of Literature
}

\author{
Pavan Tenneti ${ }^{1}$, Umar Zahid ${ }^{2}$, FNU Sagar ${ }^{2}$, Muhammed Usman ${ }^{1}$, Faiz Anwer ${ }^{3}$ \\ 1. Department of Medicine, Banner University Medical Center Tucson, Tucson, USA 2. Internal Medicine, University of \\ Arizona, Tucson, USA 3. Hematology and Oncology, University of Arizona, Tucson, USA
}

Corresponding author: Pavan Tenneti, tvpavan7@gmail.com

\begin{abstract}
We report a case of a patient with relapsed Ewing's sarcoma (ES). After receiving conventional chemotherapy (CC) and noticing chemosensitivity of the disease, we proceeded to give the patient two separate cycles of HDCT consisting of a melphalan/busulfan regimen in the first cycle and etoposide/melphalan in the second cycle. The patient proceeded to get an autologous stem cell transplant (ASCT) after each cycle of HDCT. Our patient, despite multiple poor prognostic factors, including advanced age and multiple sites of disease relapse, showed a one-year event-free survival.
\end{abstract}

Relapsed ES is associated with a poor prognosis. No treatment regimen has yet been established as a standard of care in patients with relapsed ES. We conducted a focused literature review to assess the efficacy of high-dose chemotherapy (HDCT) followed by ASCT in patients with relapsed ES. Given the improved survival outcome with HDCT followed by ASCT in our patient, we propose that its role in relapsed ES needs further assessment through large prospective, randomized controlled studies.

Received 04/03/2018 Review began 04/25/2018 Review ended 05/04/2018 Published 05/05/2018

\section{(c) Copyright 2018} Tenneti et al. This is an open access article distributed under the terms of the Creative Commons Attribution License CC-BY 3.0., which permits unrestricted use, distribution, and reproduction in any medium, provided the original author and source are credited.

Categories: Oncology

Keywords: relapsed, ewing's sarcoma, stem cell transplantation, high-dose chemotherapy

\section{Introduction}

Patients with localized primary Ewing's sarcoma (ES) have a five-year overall survival (OS) of 60 - $70 \%$ with the use of multimodality treatment [1]. In patients with primary metastatic ES, the five year OS rate is 20 $40 \%$ with treatment [1]. Approximately $30-40 \%$ of patients with localized primary ES who initially achieved remission after front-line treatment experience disease relapse, and the prognosis in these patient groups was shown to be dismal with one and five year OS of $43 \%$ and $13 \%$, respectively [2]. At the time of disease relapse, prognostic factors indicative of poor outcome include relapse time less than two years from initial diagnosis, the location of relapse at the extrapulmonary site, combined local as well as systemic relapse, and abnormally high lactate dehydrogenase (LDH) levels at initial diagnosis [3-5]. No standardized treatment has been approved for the treatment of relapsed ES. Local therapy at the site of relapse, including radical surgery, has been shown to be beneficial [5]. Conventional chemotherapy (CC) regimens given at relapse have led to response rates up to $29-68.1 \%$; response depended on the type of regimen used and site of relapse [6-10]. The event-free survival (EFS) at one to two years has been noted to be between $22.7-26 \%$ in a couple of studies [8-9]. OS rates at one to two years in other studies were shown to be about $28-61 \%$ [7-8]. The five year OS was $20-24.5 \%$ in another retrospective study [11].

Despite its reported survival benefit as a consolidation treatment after CC, high-dose chemotherapy (HDCT) and autologous stem cell transplant (ASCT) are not routinely used in the United States for relapsed Ewing's sarcoma. We present a focused literature review, along with a case report of a patient diagnosed with chemosensitive relapsed ES with an expected poor long-term prognosis based on his poor prognostic markers at relapse, who received two cycles of HDCT followed by ASCT.

\section{Case Presentation}

A 35-year-old Caucasian male presented during February 2012 with a three-month history of progressive lower back pain radiating to the left leg. Dorsal spine magnetic resonance imaging (MRI) revealed a mass involving the left ilium, sacrum, and left sacroiliac joint. It was also invading the S1-S2 left neural foramen and superior sciatic notch (Figure 1). Biopsy of the mass showed a small round blue cell malignant neoplasm, having a uniform site of morphology with a lobulated growth pattern with some of the cells having limited amounts of amphophilic cytoplasm. There was a strong immune positivity for CD99 but negative for desmin CD 163 and CD68. He was diagnosed with primary localized ES. The patient received neoadjuvant chemotherapy and adjuvant radiation therapy according to the VIVA (vincristine + ifosfamide + doxorubicin + actinomycin D) regimen. He completed radiotherapy to the primary site in August 2012 with 


\section{Cureus}

concurrent ifosfamide and etoposide. All planned treatment was completed in January 2013. The patient was under close follow-up, and in May of 2014, he presented with multiple lung and two pleural lesions. Biopsy confirmed the lesions to be a relapse of ES with metastasis to lungs (Figures 2, 3). In addition, pleural fluid immunohistochemical stains demonstrated the neoplastic cells to be positive for CD99 and negative for MAK-6, synaptophysin, neuron-specific enolase (NSE), and CD56, consistent with metastatic ES. The patient received five cycles of topotecan and cyclophosphamide. A follow-up computed tomography (CT) of the chest in July 2014, before cycle 3 , showed interval decrease in the metastatic lesions, consistent with chemosensitive disease. A positron emission tomography/computed tomography (PET/CT) scan during August 2014, after five cycles of topotecan/cyclophosphamide, showed stable metastatic disease in the form of pulmonary nodules and pleural involvement. Autologous stem cells were collected during a single leukapheresis session before the first high-dose chemotherapy (HDCT). The patient received high-dose chemotherapy in October of 2014 (busulfan, $0.8 \mathrm{mg} / \mathrm{kg}$ IV (intravenous) q six hours x 16 doses; melphalan,

$140 \mathrm{mg} / \mathrm{m}^{2}$ ) and received CD34+ cells $4.24 \times 10 \mathrm{e} 6 / \mathrm{kg}$ infused as an autologous stem cell rescue. The second round of planned consolidative high-dose chemotherapy was given during July 2015 (etoposide/melphalan regimen - etoposide, IV $400 \mathrm{mg} / \mathrm{m}^{2}$, total three doses (Days 2, 3, 4) and melphalan, IV $100 \mathrm{mg} / \mathrm{m}^{2}$, one dose (on Day 1)) followed by autologous peripheral blood stem cell rescue. During the first cycle of chemotherapy, the patient developed mucositis, neutropenic fever, and diarrhea secondary to Clostridium difficile colitis. After the second cycle of HDCT, the patient developed mucositis and transient elevation of liver function tests but these abnormalities resolved over a few weeks.

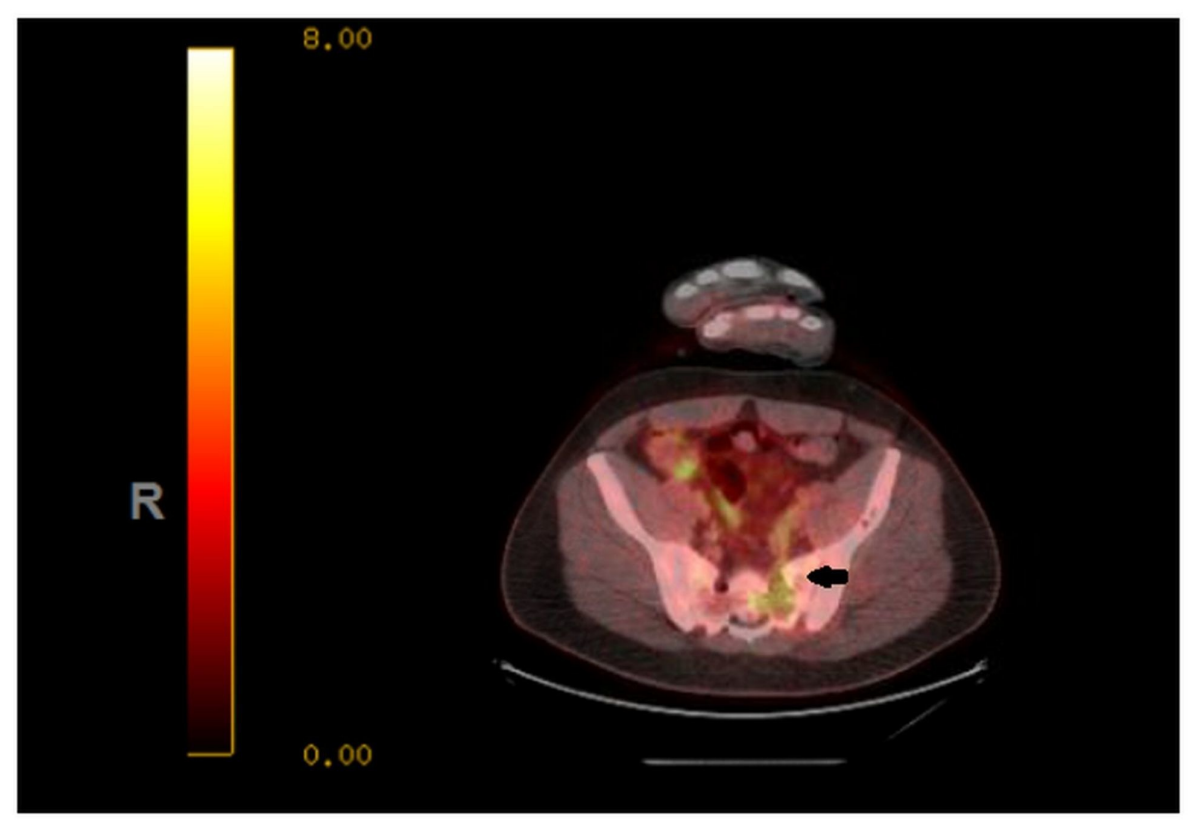

FIGURE 1: MRI scan of the pelvis (2012) - Ewing's sarcoma in left sacrum/ilium locally involving neuroforamina, paraspinous, and gluteal muscles

MRI: magnetic resonance imaging 


\section{Cureus}

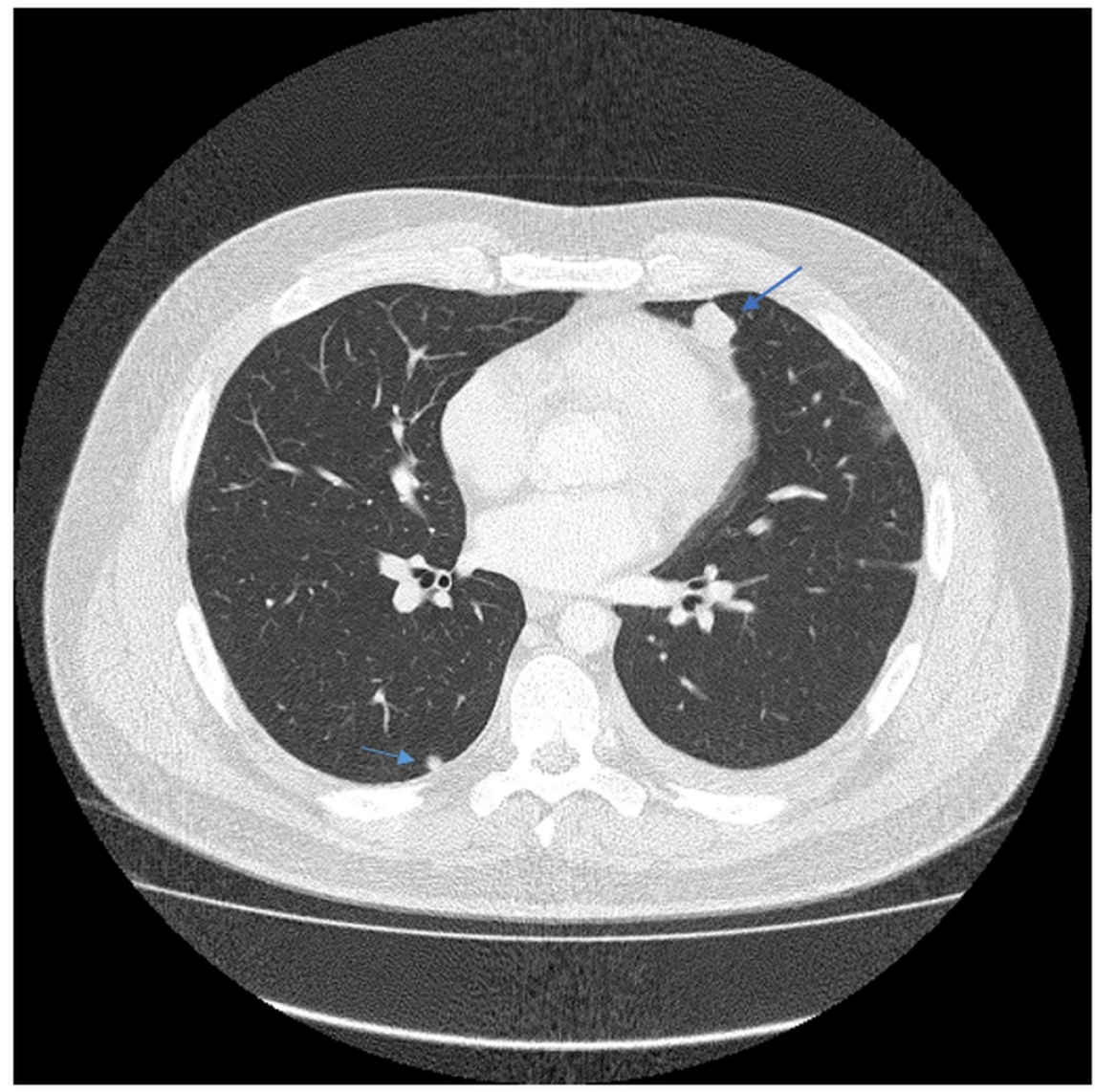

FIGURE 2: CT scan chest (May 2014)

Relapsed Ewing's sarcoma in the lungs with multiple pulmonary nodules, the largest being $11.8 \times 9.8 \mathrm{~mm}$ (arrow on right)

CT: computed tomography 


\section{Cureus}

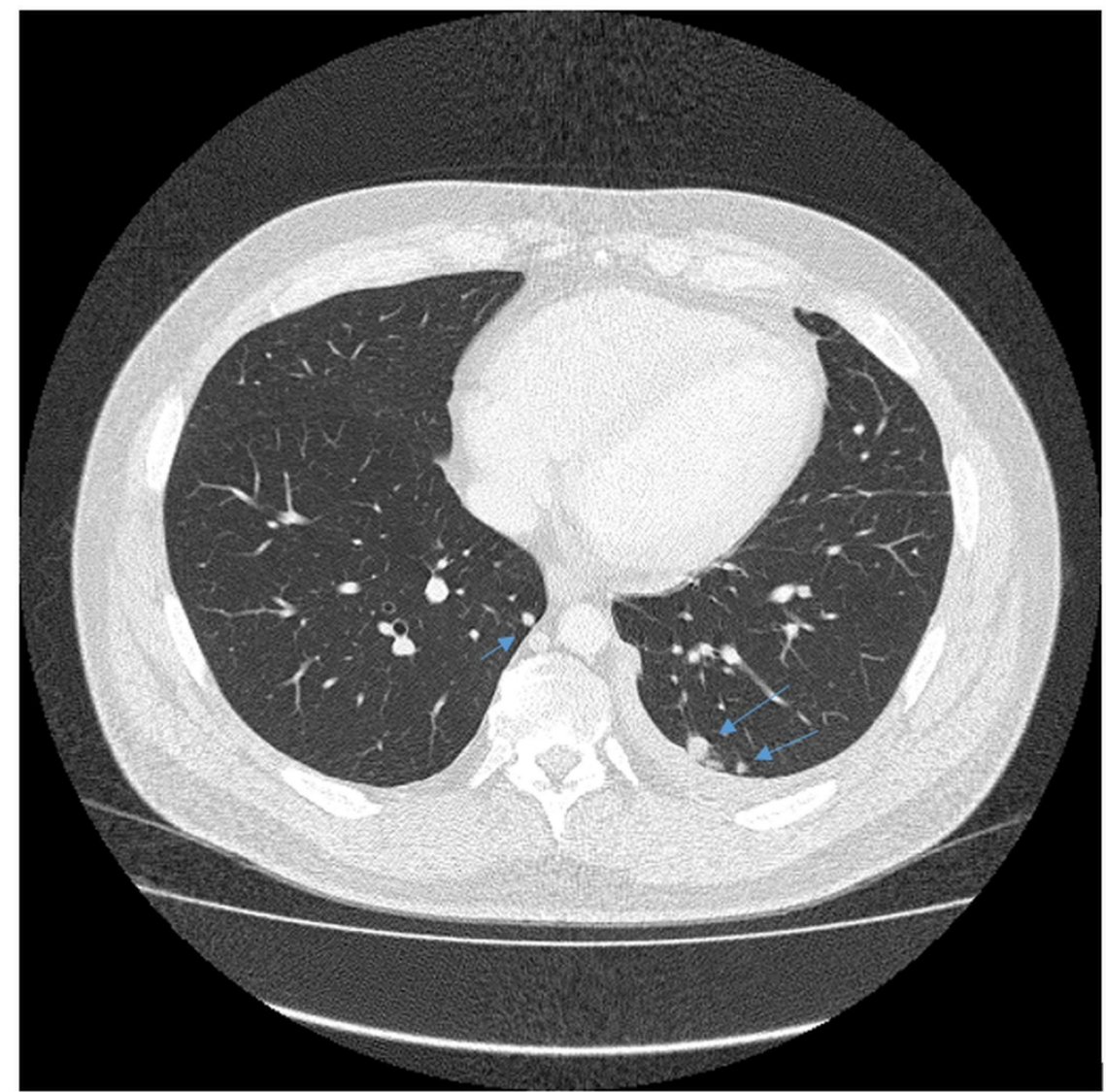

\section{FIGURE 3: CT scan chest (May 2014)}

Relapsed Ewing's sarcoma in the lungs with multiple pulmonary nodules

CT: Computed tomography

HDCT achieved 12 months of progression-free survival (PFS); however, on a subsequent PET scan performed during October 2015, the patient showed disease progression. An increase in the size of the metastatic lesions was noted, along with new areas of involvement of malignancy. The patient subsequently received six cycles of pembrolizumab, an antibody against programmed cell death 1 (PD-1) receptor. Subsequent imaging studies showed a progression of the disease, and the patient subsequently received cyclophosphamide, vincristine, dactinomycin (alternating with ifosfamide), and etoposide during March of 2016. The patient developed significant toxicities, bone marrow suppression, and in the presence of progressive disease during June 2016, he chose hospice care (Figure 4). 


\section{Cureus}

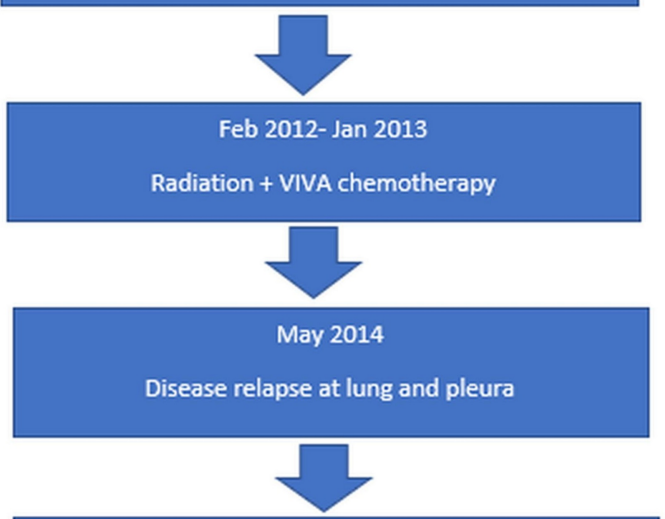

May 2014 - Aug 2014

Conventional dose chemotherapy

(5 cycles of Topotecan+ Cyclophosphamide)
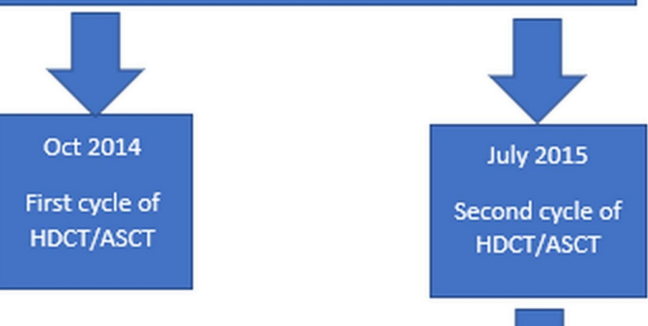

October 2015

Progression of disease on PET Scan

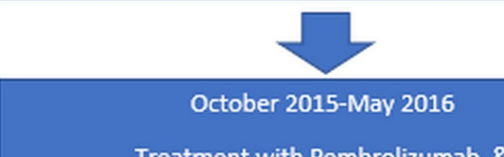

Treatment with Pemhrolizumah \&

Cyclophosphamide/Vincristine/Daptomycin and Ifosfamide/Etoposide

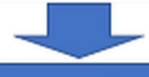

June 2016

Comfort measures/Hospice care

\section{FIGURE 4: Flowchart showing sequence of events in patient history}

ASCT: autologous stem cell transplant; HDCT: high-dose chemotherapy; PET: positron emission tomography; VIVA: vincristine + ifosfamide + doxorubicin + actinomycin D

\section{Discussion}

In patients with relapsed ES, there is no established standard of care salvage chemotherapy regimen. Regarding conventional salvage options, different regimens have been tried with variable results (Table 1). A phase II study using the ICE (ifosfamide, carboplatin, and etoposide) regimen showed an overall response rate (ORR) of $51 \%$ and one-year (yr) and two-yr OS rates of $49 \%$ and $28 \%$, respectively [7]. Studies conducted with non-ifosfamide regimens, such as docetaxel along with gemcitabine, showed an ORR of $29 \%$ and a median duration of response of 4.8 months [6]. The ORR was $44 \%$, with a two-yr EFS of $26 \%$ in a study with 54 relapsed ES patients when cyclophosphamide and topotecan were used [8]. Irinotecan and temozolomide resulted in an ORR of $63 \%$ and a time to progression of eight months [10]. The ORR was $68 \%$ with an EFS of 
$22.7 \%$ at 10.3 months in a study where patients received the VIT (vincristine, irinotecan, temozolomide) regimen [9]. Another retrospective study on relapsed ES, conducted on 107 patients using either etoposide and cisplatin or etoposide and carboplatin, showed a median EFS of 6.5 and 14 months, respectively, with five-yr OS rates of $20 \%$ and $24.5 \%$, respectively [11]. Collectively, these data suggest the need for further improvement in the treatment outcomes in ES patients.

\begin{tabular}{|l|l|l|l|l|l|}
\hline Study & Agents used & Number of patients & Response rate & Overall survival & Event free survival \\
\hline Navid et al. [6] & $\mathrm{G}+\mathrm{D}$ & 22 & $29 \%$ & $\mathrm{NL}$ & $\mathrm{NL}$ \\
\hline Van Winkle et al. [7] & $\mathrm{I}+\mathrm{Ca}+\mathrm{E}$ & 97 & $51 \%$ & $1 \mathrm{yr}: 49 \% 2 \mathrm{yr}: 28 \%$ & $\mathrm{NL}$ \\
Hunold et al. [8] & $\mathrm{To}+\mathrm{Cy}$ & 54 & $44.4 \%$ & $1 \mathrm{yr}: 61 \%$ & $23.1 \mathrm{~m}=25.9 \%$ \\
Raciborska et al. [9] & $\mathrm{V}+\mathrm{Ir}+\mathrm{Te}$ & 22 & $68.1 \%$ & $\mathrm{NL}$ & $10.3 \mathrm{~m}=22.7 \%$ \\
Casey et al. [10] & $\mathrm{Ir}+\mathrm{Te}$ & 20 & $63.1 \%$ & $\mathrm{NL}$ & $\mathrm{NL}$ \\
Van Maldegem et al. [11] & $\mathrm{E}+\mathrm{Ca} / \mathrm{Ci}$ & 107 & $\mathrm{NL}$ & $5 \mathrm{yr}: 20-24.5 \%$ & $\mathrm{NL}$ \\
\hline
\end{tabular}

\section{TABLE 1: Outcomes of Relapsed Patients in Studies Utilizing Conventional Dose Chemotherapy}

Ca: carboplatin; Ci: cisplatin; Cy: cyclophosphamide; D: docetaxel; E: etoposide; G: gemcitabine; I: ifosfamide; Ir: irinotecan; m: months; Te: temozolomide; To: topotecan; V: vincristine; NL: Not listed

Patients presenting with distant site, non-pulmonary metastasis at the time of relapse have particularly poor long-term outcomes with the use of conventional chemotherapy regimens. In a 2009 retrospective study by Casey et al. with 20 patients with refractory/relapsed ES who were treated with irinotecan and temozolomide, the median time to progress in patients with relapse at multiple sites $(\mathrm{n}=6)$ was 2.4 months in comparison to 24.3 months $(p=0.00)$ for patients with single site disease relapse $(n=9)$ [10]. In another retrospective study by Leavey et al. in $2008(\mathrm{n}=262)$, the median duration of survival for patients with distant relapse, other than lung, was nine months [4]. Bacci et al., who published a study of 195 patients in 2003, noted the EFS at five years for a subgroup of patients with distant relapse was $8.6 \%$. The median duration of survival was 19.3 months [3]. In another study of 71 patients, Rodriguez-Galindo et al. showed a five-year OS for patients with a distant relapse to be only $17.5 \%$ [5].

HDCT, followed by ASCT, is based on the observation that the dose intensity of chemotherapy can determine outcomes in many malignancies. Dose-response is steep for both toxic and therapeutic effects. Preclinical studies documented a direct correlation between the dose of chemotherapy and tumor cytotoxicity. A multiple log increase in tumor cell death can be possible with a three to tenfold increase in the dosage of chemotherapy, particularly for alkylating agents. Myelosuppression is one of the major side effects at this dose [12]. ASCT helps to counter this by rescuing the marrow and allows for dose escalation [13].

Through a systemic literature search, we identified seven retrospective studies where HDCT, followed by ASCT, was given in patients with relapsed ES $(n=708)$ (Table 2). The outcomes of patients with local and metastatic relapse who received HDCT followed by ASCT after CC were studied by McTiernan et al. 2006 ( $\mathrm{n}=$ 33) [14]. The two and five-year EFS rates were 43 and 39\%, respectively. The corresponding OS rates were 51 and $43 \%$, respectively. Fifty-five patients with local and metastatic relapse were studied by Barker et al. in 2005 [15]. All patients were treated with CC; in addition, HDCT, followed by ASCT, was given to patients who showed either complete response(CR) or partial response (PR). The EFS and OS rates at five years for patients treated with HDCT/ASCT was 61 and 77\%, respectively. On the other hand, the reported five year EFS and OS for patients that were treated with only CC was $7 \%$ each (p values not reported). In an additional study by Ferrari et al. in 2015, the five-year OS rate was $50 \%$ for patients who received CC followed by HDCT/ASCT $(n=107)$ [16]. Shanker et al. 2003 [17] reported OS of $28 \%$ at 3.5 years for patients with relapsed ES who got HDCT/ASCT after CC. The OS of $21 \%$ at three years was reported by Palmerini et al. (Palmerini et al.: High-dose chemotherapy with autologous stem cell transplantation for relapsed Ewing's sarcomaabstract, ASCO annual meeting, May 2009. http://ascopubs.org/doi/abs/10.1200/jco.2009.27.15s.10545) in another study for patients with relapsed ES where HDCT/ASCT was given after CC. The outcomes of patients from the CESS (Cooperative Ewing Sarcoma study group) registry with local and metastatic relapse was reported by Rasper et al. $2014(n=239)$ [18]. All patients received CC. In addition, 73 patients who showed chemosensitivity (either CR/PR) received HDCT/ASCT. The two- and five-year EFS for patients who were treated with HDCT were 44 and $24 \%$, respectively, whereas they were $10 \%$ and $6 \%$, respectively, in patients treated with only CC $(p=0.01)$. The two- and five-year OS rates for patients who received HDCT were $66 \%$ and $42 \%$, respectively, compared to $22 \%$ and $10 \%$ in patients with only CC ( $p=0.01)$. The outcomes of 138 patients with metastatic disease at relapse was studied by Bacci et al. [3]. Ninety-five patients who received only CC did not survive longer than five years. Also, none of the 15 patients who received HDCT as the induction treatment without CC survived longer than five years, suggesting that CC may be required, 
followed by HDCT consolidation to further improve survival. To summarize, for most studies consisting of only relapsed patients (except for one), EFS rates at two and five years ranged from 42 - $44 \%$ and 24 - $43 \%$, respectively. The OS rates at two and three to five years ranged from 50 - $66 \%$ and 21 - 50\%, respectively. The patients in the Bacci et al. study did not do well because the disease was metastatic at relapse and they did not get CC prior to HDCT [3].

\begin{tabular}{|c|c|c|c|c|c|c|c|c|c|}
\hline Study & $\begin{array}{l}\text { Median } \\
\text { age } \\
\text { (yr.) }\end{array}$ & $\begin{array}{l}\text { No. } \\
\text { of } \\
\text { pts }\end{array}$ & $\begin{array}{l}\text { Type of } \\
\text { relapse } \\
\text { (No. of } \\
\text { pts) }\end{array}$ & Chemotherapy & HDCT $\left(\mathrm{mg} / \mathrm{m}^{2} ; \mathrm{mg} / \mathrm{kg}\right)$ & $\begin{array}{l}\text { Source } \\
\text { of } \\
\text { stem } \\
\text { cell }\end{array}$ & $\begin{array}{l}\text { Response } \\
\text { (No. of } \\
\text { pts) }\end{array}$ & EFS & OS \\
\hline $\begin{array}{l}\text { Rasper et } \\
\text { al. } 2014 \\
{[18]}\end{array}$ & NL & 239 & $\begin{array}{l}\text { Local (42), } \\
\text { Distant } \\
\text { (142), } \\
\text { Combined } \\
(30)\end{array}$ & $\begin{array}{l}\mathrm{T} / \mathrm{C}, \mathrm{I} / \mathrm{Te}, \\
\text { If/E/Carboplatin }\end{array}$ & $\begin{array}{l}\text { C1: Busulfan/Melphalan (NL); C2: } \\
\text { Treosulfan/Melphalan (NL); Others: } \Omega\end{array}$ & NL & $\begin{array}{l}\text { C1: CR (5) } \\
\text { PR (2) C2: } \\
\text { CR (19) } \\
\text { PR (8) }\end{array}$ & $\begin{array}{l}2 \text { yr HDCT - } \\
44 \% \text { w/o HDCT- } \\
10 \% \text { ( } p \text { value: } \\
0.01) ; 5 \text { yr. } \\
\text { HDCT }-24 \% \\
\text { w/o HDCT - } 6 \% \\
\text { ( } p \text { value: } 0.01 \text { ) }\end{array}$ & $\begin{array}{l}2 \text { yr HDCT- } \\
66 \% \text { w/o } \\
\text { HDCT-22\%; } 5 \\
\text { yr HDCT - } \\
42 \% \text { w/o } \\
\text { HDCT - } 10 \% \\
\text { (p value: } 0.01 \text { ) }\end{array}$ \\
\hline $\begin{array}{l}\text { Barker et } \\
\text { al. } 2005 \\
{[15]}\end{array}$ & 13.5 & 55 & $\begin{array}{l}\text { Local (6); } \\
\text { Distant } \\
\text { (39); } \\
\text { Combined } \\
(10)\end{array}$ & $\begin{array}{l}\text { VDC - IE; } \\
\text { VACIME; VDC- } \\
\text { A; VDC-A-M }\end{array}$ & Busulfan/melphalan/ thiotepa (NL) & PBSC & $\begin{array}{l}\text { CR/PR } \\
(27)\end{array}$ & $\begin{array}{l}5 \text { yr HDCT: } 61 \% \\
\text { w/o HDCT: } 7 \%\end{array}$ & $\begin{array}{l}5 \text { yr HDCT: } \\
77 \% \text { w/o } \\
\text { HDCT: } 7 \%\end{array}$ \\
\hline $\begin{array}{l}\text { Ferrari et } \\
\text { al. } 2015 \\
{[16]}\end{array}$ & NL & 107 & $\begin{array}{l}\text { Local (11); } \\
\text { Distant } \\
(96)\end{array}$ & VDCAIE & $\begin{array}{l}\text { Busulfan/melphalan (4 mg/kg and } 140 \\
\mathrm{mg} / \mathrm{m}^{2} \text { ) }\end{array}$ & PBSC & NL & NL & $\begin{array}{l}\text { HDCT: } 5 \text { yr OS } \\
50 \%\end{array}$ \\
\hline $\begin{array}{l}\text { Palmerini } \\
\text { et } \\
\text { al. } 2009 \\
\text { abstract }\end{array}$ & 17 & 72 & Local (11) & NL & $\begin{array}{l}\text { Busulfan/melphalan (4 mg/kg and } 140 \\
\mathrm{mg} / \mathrm{m}^{2} \text { ) Palliative }\end{array}$ & NL & NL & NL & $\begin{array}{l}\text { HDCT: } 3 \text { yr OS } \\
21 \%\end{array}$ \\
\hline $\begin{array}{l}\text { McTiernan } \\
\text { et al. } 2006 \\
{[14]}\end{array}$ & 19 & 33 & $\begin{array}{l}\text { Local (11) } \\
\text { Distant } \\
\text { (18); } \\
\text { Combined } \\
\text { (4) }\end{array}$ & Ca, E C A I D V & $\begin{array}{l}\text { Busulfan } / \mathrm{melphalan}\left(600 \mathrm{mg} / \mathrm{m}^{2} / 140\right. \\
\left.\mathrm{mg} / \mathrm{m}^{2}\right)-22 \text { pts Melphalan/etoposide } \\
\left(130 \mathrm{mg} / \mathrm{m}^{2} / 60 \mathrm{mg} / \mathrm{m}^{2}\right)-7 \mathrm{pts} \text { TBI } \\
\text { Melphalan/Cytoxan }(16 \mathrm{mg} / \mathrm{kg} / 60 \\
\mathrm{mg} / \mathrm{kg})-1 \text { pt. Melphalan }\left(150 \mathrm{mg} / \mathrm{m}^{2}\right) \\
-3 \mathrm{pts}\end{array}$ & $\begin{array}{l}\text { PBSC } \\
\text { BSC }\end{array}$ & $\begin{array}{l}\text { Prior to } \\
\text { HDCT: CR } \\
\text { (14) PR } \\
\text { (10) Post- } \\
\text { HDCT: CR } \\
\text { (21) PR (2) }\end{array}$ & $\begin{array}{l}2 \text { yr EFS } 42.5 \% \\
5 \text { yr EFS } 38.5 \%\end{array}$ & $\begin{array}{l}2 \text { yr OS } \\
50.7 \% ; 5 \text { yr } \\
\text { OS } 42.8 \%\end{array}$ \\
\hline $\begin{array}{l}\text { Shankar } \\
\text { et al. } 2003 \\
{[17]}\end{array}$ & 14 & 64 & Local (11) & $\begin{array}{l}\mathrm{Ca} / \mathrm{E}, \mathrm{C} / \mathrm{E} / \mathrm{Ca} \\
\mathrm{C} / \mathrm{E}\end{array}$ & Melphalan (NL) TBI & $\begin{array}{l}\text { PBSC } \\
\text { BSC }\end{array}$ & NL & 3.5 yr EFS $14 \%$ & 3.5 yr OS $28 \%$ \\
\hline $\begin{array}{l}\text { Bacci et } \\
\text { al. } 2003 \\
{[3]}\end{array}$ & 18 & 138 & $\begin{array}{l}\text { Distant } \\
\text { (138) }\end{array}$ & none & Melphalan (NL) Busulfan (NL) & $\begin{array}{l}\text { PSBC } \\
\text { BSC }\end{array}$ & NL & NL & $\begin{array}{l}5 \text { yr only } \\
\text { HDCT - } 0 \% \\
\text { w/o HDCT - } \\
0 \%\end{array}$ \\
\hline
\end{tabular}

\section{TABLE 2: Studies Using HDCT and ASCT in Relapsed Ewing's Sarcoma}

A: dactinomycin; ASCT: autologous stem cell transplant; C: cyclophosphamide; Ca: Carboplatin; CR: complete response; D: doxorubicin; E: etoposide; EFS: event-free survival; HDCT: high-dose chemotherapy; I: ifosmade; Ir: irinotecan; M: methotrexate; NL: Not listed; No: number; OS: overall survival; PR: partial response; SCT: stem cell transplant; T: topotecan; TBI: total body irradiation; Te: temozolomide; V: vincristine; $\Omega$ : topotecan, Cytoxan, irinotecan; C1: High-dose chemotherapy regimen 1; C2: High-dose chemotherapy regimen 2; PSBC: Peripheral blood stem cells: BSC: Bone marrow stem cells.

The patient reported in our case report was an adult male with relapsed ES who had a relapse at multiple sites, including the lung and pleura. Based on the review of poor prognostic factors, patients with nonpulmonary relapse or relapse at multiple distant sites have a poor prognosis with traditional chemotherapy. In addition, some studies showed that patients with advanced age have poor outcomes with ES [19]. We decided to give HDCT with ASCT after CC in a patient who had chemosensitive relapsed ES, as our literature review showed a possible benefit of HDCT for such patients. Our patient received two cycles of HDCT followed by ASCT, achieved about 12 months of PFS, and progressed four months after completion of the 
second cycle. Subsequently, it did not show a response to other treatments, including PD 1 inhibitor (pembrolizumab) and additional salvage chemotherapy. He ultimately chose hospice care.

\section{Conclusions}

Patients with relapsed ES are associated with a poor prognosis when treated with conventional chemotherapy. The worst prognosis is seen in patients with multiple distant and non-pulmonary sites of relapse. Through a literature search, we identified studies that showed the potential benefit of HDCT followed by ASCT in chemosensitive disease in relapsed ES. Given the positive results in the literature (mainly, multiple large retrospective studies), the role of HDCT followed by ASCT in relapsed ES needs to be further defined by prospective, randomized controlled studies.

\section{Additional Information \\ Disclosures}

Human subjects: Consent was obtained by all participants in this study. Conflicts of interest: In compliance with the ICMJE uniform disclosure form, all authors declare the following: Payment/services info: All authors have declared that no financial support was received from any organization for the submitted work. Financial relationships: All authors have declared that they have no financial relationships at present or within the previous three years with any organizations that might have an interest in the submitted work. Other relationships: All authors have declared that there are no other relationships or activities that could appear to have influenced the submitted work.

\section{References}

1. Paulussen M, Bielack S, Jürgens H, et al.: Ewing's sarcoma of the bone: ESMO clinical recommendations for diagnosis, treatment and follow-up. Ann Oncol. 2009, 20:140-42. 10.1093/annonc/mdp155

2. Stahl M, Ranft A, Paulussen M, et al.: Risk of recurrence and survival after relapse in patients with Ewing sarcoma. Pediatr Blood Cancer. 2011, 57:549-53. 10.1002/pbc.23040

3. Bacci G, Ferrari S, Longhi A, et al.: Therapy and survival after recurrence of Ewing's tumors: the Rizzoli experience in 195 patients treated with adjuvant and neoadjuvant chemotherapy from 1979 to 1997 . Ann Oncol. 2003, 14:1654-59. 10.1093/annonc/mdg457

4. Leavey PJ, Mascarenhas L, Marina N, et al.: Prognostic factors for patients with Ewing sarcoma (EWS) at first recurrence following multi-modality therapy: A report from the Children's Oncology Group. Pediatr Blood Cancer. 2008, 51:334-38. 10.1002/pbc.21618

5. Rodriguez-Galindo C, Billups C, Kun L, et al.: Survival after recurrence of Ewing tumors: the St Jude Children's Research Hospital experience, 1979-1999. Cancer. 2002, 94:561-69. 10.1002/cncr.10192

6. Navid F, Willert JR, McCarville MB, et al.: Combination of gemcitabine and docetaxel in the treatment of children and young adults with refractory bone sarcoma. Cancer. 2008, 113:419-25. 10.1002/cncr.23586

7. Van Winkle P, Angiolillo A, Krailo M, et al.: Ifosfamide, carboplatin, and etoposide (ICE) reinduction chemotherapy in a large cohort of children and adolescents with recurrent/refractory sarcoma: The Children's Cancer Group (CCG) experience. Pediatr Blood Cancer. 2005, 44:338-47. 10.1002/pbc.20227

8. Hunold A, Weddeling N, Paulussen M, et al.: Topotecan and cyclophosphamide in patients with refractory or relapsed Ewing tumors. Pediatr Blood Cancer. 2006, 47:795-800. 10.1002/pbc.20719

9. Raciborska A, Bilska K, Drabko K, et al.: Vincristine, irinotecan, and temozolomide in patients with relapsed and refractory Ewing sarcoma. Pediatr Blood Cancer. 2013, 60:1621-25. 10.1002/pbc.24621

10. Casey DA, Wexler LH, Merchant MS, et al.: Irinotecan and temozolomide for Ewing sarcoma: the Memorial Sloan-Kettering experience. Pediatr Blood Cancer. 2009, 53:1029-34. 10.1002/pbc.22206

11. van Maldegem AM, Benson C, Rutkowski P, et al.: Etoposide and carbo-or cisplatin combination therapy in refractory or relapsed Ewing sarcoma: A large retrospective study. Pediatr Blood Cancer. 2015, 62:40-44. $10.1002 / p b c .25230$

12. Frei E 3rd, Canellos GP: Dose: a critical factor in cancer chemotherapy . Am J Med. 1980, 69:585-94. 10.1016/0002-9343(80)90472-6

13. Seeger RC, Reynolds CP: Treatment of high-risk solid tumors of childhood with intensive therapy and autologous bone marrow transplantation. Pediatr Clin North Am. 1991, 38:393-424. 10.1016/S00313955(16)38084-1

14. McTiernan A, Driver D, Michelagnoli MP, et al.: High dose chemotherapy with bone marrow or peripheral stem cell rescue is an effective treatment option for patients with relapsed or progressive Ewing's sarcoma family of tumours. Ann Oncol. 2006, 17:1301-1305. 10.1093/annonc/mdl108

15. Barker LM, Pendergrass TW, Sanders JE, Hawkins DS: Survival after recurrence of Ewing's sarcoma family of tumors. J Clin Oncol. 2005, 23:4354-62. 10.1200/JCO.2005.05.105

16. Ferrari S, Luksch R, Hall KS, et al.: Post-relapse survival in patients with Ewing sarcoma. Pediatr Blood Cancer. 2015, 62:994-99. 10.1002/pbc.25388

17. Shankar AG, Ashley S, Craft AW, Pinkerton CR: Outcome after relapse in an unselected cohort of children and adolescents with Ewing sarcoma. Med Pediatr Oncol. 2003, 40:141-47. 10.1002/mpo.10248

18. Rasper M, Jabar S, Ranft A, et al.: The value of high-dose chemotherapy in patients with first relapsed Ewing sarcoma. Pediatr Blood Cancer. 2014, 61:1382-86. 10.1002/pbc.25042

19. Baldini EH, Demetri GD, Fletcher CD, et al.: Adults with Ewing's sarcoma/primitive neuroectodermal tumor: adverse effect of older age and primary extraosseous disease on outcome. Ann Surg. 1999, 230:79-86. 10.1097/00000658-199907000-00012 